\title{
An Empirical Study on Effecting Human Rights Awareness on Job Satisfaction: Based on Caregiver
}

\author{
Jae-Oh Kim ${ }^{1}$ and Ha-Kyun $\mathrm{Kim}^{2}$ \\ ${ }^{1}$ Doctoral Student of Graduate School of Information Systems, Pukyong National \\ Univ. 45, Yongso-ro, Nam-Gu, Busan, Korea \\ ${ }^{2}$ Professor (Corresponding Author) of Division of Business, Pukyong National Univ. \\ 45, Yongso-ro, Nam-Gu. Busan, Korea \\ I'ookims@nate.com, ${ }^{2}$ kimhk@pknu.ac.kr
}

\begin{abstract}
This study focuses on analyzing the relationship between caregiver's human rights awareness on work ethic and job satisfaction. The summary of the study is as follows. The test results of Hypothesis 1 are as follows. First, human rights awareness had a significant effect on basic work ethics. Second, human rights awareness had a significant effect on work ethics. Third, human rights awareness had a significant effect on fellow workers. Fourth, human rights awareness had a significant effect on facility ethic. The test results of Hypothesis 2 are as follows. Fifth, basic ethics had not a significant effect on job satisfaction. Sixth, work ethic had not a significant effect on job satisfaction. Seventh, fellow workers had a significant effect on job satisfaction. Eighth, facility ethics had a significant effect on job satisfaction.
\end{abstract}

Keywords: Human rights awareness, Work ethic, Job satisfaction, Caregiver

\section{Introduction}

Caregiver care for the elderly, represented by long-term care services for the elderly, is actively developed as the caregiver is the core. Due to the nature of the caregiver and the elderly providing services through people, the job-related attitudes of the caregiver determine the quality of services that guarantee the life of the elderly. This is why the awareness of human rights and ethical values are important for care workers in carrying out care services. As such, caregivers should take senior citizens' rights advocacy as their primary value and have sensitive human rights awareness and strong ethical standards as a professional.

The caregiver's human rights awareness at the site of care can improve the satisfaction of the elderly who receive services. In addition, job satisfaction will be positively changed by strengthening the occupational ethic of caregivers. Prior studies on the effects of caregiver's human rights awareness on job ethics and job satisfaction have been insufficient. The purpose of this study is to examine the correlation between caregiver's human rights awareness, work ethic and job satisfaction through the structural equation.

\section{Theoretical background}

\subsection{Human rights awareness}

Article history:

Received (April 8, 2019), Review Result (July 30, 2019), Accepted (September29, 2019) 
Human rights awareness is a compound word of Human Rights and Consciousness, which includes an accurate judgment on the situation in which human rights are violated, emotional sharing of human rights violations, responsibility for solving the situation and a willingness to act [1]. In 2008, human rights education evaluation tools developed by the National Human Rights Commission of Korea, and the revised study, measured the human rights awareness of caregivers in terms of equality, liberty, survival and social rights [2].

\subsection{Work ethic}

The ethical attitude that caregivers should have is as follows [3]. First, caregivers should respect those who need help as a person. Second, check the motives for becoming a caregiver and maintain a humble attitude. Third, caregivers should work with responsibility in a sincere and calm manner.

\subsection{Job satisfaction}

Job satisfaction refers to the individual's subjective emotional state or attitude toward the job. In particular, since caregivers deliver services on a daily basis with the service subjects, job satisfaction reflects their subjective well-being. In addition to affecting and consequently affecting the quality of care, there is a direct relationship with customer satisfaction [4].

\section{Research design}

\subsection{Research model}

This study focuses on analyzing the relationship between caregiver's human rights awareness, work ethics (basic ethics, elderly ethics, fellow ethics, facility ethics) and job satisfaction. The research model is presented in [Figure 1].

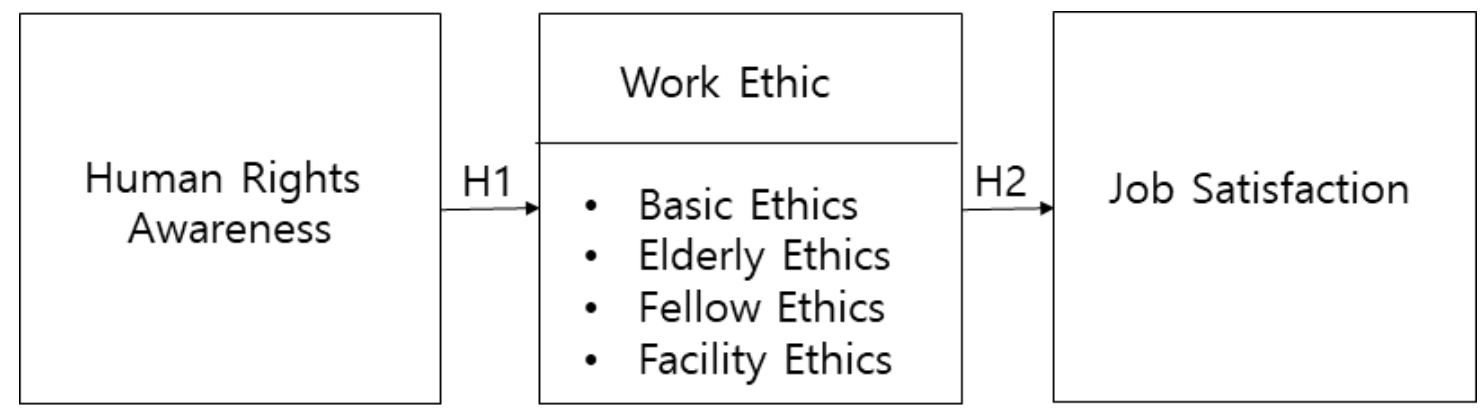

Figure 1. Research model

\subsection{Research hypothesis}

\subsubsection{Hypothesis about human rights awareness and work ethic}

Based on the National Human Rights Commission's human rights education text books, the types of elderly human rights can be classified into five types: liberty rights, equal rights, survival rights, social rights, and suffrage [5]. Based on this, the hypothesis revised to fit the human rights awareness of caregiver is as follows.

Hypothesis H1 Human rights awareness has a significant impact on work ethics. 
Hypothesis H1-1 Human rights awareness has a significant impact on basic ethics.

Hypothesis H1-2 Human rights awareness has a significant impact on the elderly ethics.

Hypothesis H1-3 Human rights awareness has a significant impact on fellow ethics.

Hypothesis H1-4 Human rights awareness has a significant impact on facility ethics.

\subsubsection{Hypothesis about work ethic and job satisfaction}

The main factors affecting the job satisfaction of caregivers were categorized into four categories. There are basic ethics, elderly ethics, fellow ethics, and facility ethics. Based on previous studies, the hypothesis was set as follows.

Hypothesis H2 Work ethics has a significant impact on job satisfaction.

Hypothesis H2-1 Basic ethics have a significant impact on job satisfaction.

Hypothesis H2-2 Elderly ethics have a significant effect on job satisfaction.

Hypothesis H2-3 Fellow ethics have a significant impact on job satisfaction.

Hypothesis H2-4 Facility ethics have a significant impact on job satisfaction.

\subsection{Empirical analysis and results}

\subsubsection{Data collection and sample characteristics}

A total of 85 users answered the survey. $92 \%$ of the respondents are female and $8 \%$ are male. The distribution by age was $34 \%$ in the 50 s and $40 \%$ in the 60 s and $74 \%$ in the 50 s and over.

\subsubsection{Analysis method of data}

For the analysis of the survey, the structural model used Smart PLS 2.0.

\subsubsection{Verification of research model}

For the structural model, Smart PLS 2.0 was used. Through the structural model, the path coefficient and the coefficient of determination (R2) between the variables of the research model were derived. It is expressed goodness of fit below 0.13 as 'high' if the R2 value is more than 0.26 and 'middle' if $0.26 \sim 0.13$ [6]. The coefficient of determination for basic ethics (0.313), elderly ethics (0.378), and job satisfaction (0.464) was found to be 'up'. Fellow ethics $(0.134)$ and facility ethics $(0.129)$ can be rated as medium.

Table 1. Reliability and internal consistency

\begin{tabular}{|c|c|c|c|c|}
\hline Variables & Factor Loading & AVE & C. R. & Cronbach's $\alpha$ \\
\hline \multirow{4}{*}{ Human rights awareness } & 0.771 & \multirow{4}{*}{0.444} & \multirow{4}{*}{0.755} & \multirow{4}{*}{0.586} \\
\hline & 0.706 & & & \\
\hline & 0.699 & & & \\
\hline & 0.441 & & & \\
\hline \multirow{3}{*}{ Basic ethics } & 0.797 & \multirow{3}{*}{0.504} & \multirow{3}{*}{0.752} & \multirow{3}{*}{0.530} \\
\hline & 0.666 & & & \\
\hline & 0.659 & & & \\
\hline \multirow{3}{*}{ Elderly ethics } & 0.641 & \multirow{3}{*}{0.608} & \multirow{3}{*}{0.821} & \multirow{3}{*}{0.676} \\
\hline & 0.860 & & & \\
\hline & 0.822 & & & \\
\hline
\end{tabular}




\begin{tabular}{|c|c|c|c|c|}
\hline \multirow{2}{*}{ Fellow ethics } & 0.927 & \multirow{2}{*}{0.789} & \multirow{2}{*}{0.882} & \multirow{2}{*}{0.740} \\
\hline & 0.848 & & & \\
\hline \multirow{3}{*}{ Facility ethics } & 0.821 & \multirow{3}{*}{0.609} & \multirow{3}{*}{0.823} & \multirow{3}{*}{0.687} \\
\hline & 0.819 & & & \\
\hline & 0.695 & & & \\
\hline \multirow{3}{*}{ Job satisfaction } & 0.772 & \multirow{3}{*}{0.664} & \multirow{3}{*}{0.855} & \multirow{3}{*}{0.748} \\
\hline & 0.858 & & & \\
\hline & 0.811 & & & \\
\hline
\end{tabular}

Table 2. Correlation and discriminant validity

\begin{tabular}{|c|c|c|c|c|c|c|c|}
\hline Variables & AVE & 1 & 2 & 3 & 4 & 5 & 6 \\
\hline Human rights awareness & 0.444 & $\mathbf{0 . 6 6 6}$ & & & & & \\
\hline Basic ethics & 0.504 & 0.559 & $\mathbf{0 . 7 1 0}$ & & & & \\
\hline Elderly ethics & 0.608 & 0.615 & 0.604 & $\mathbf{0 . 7 8 0}$ & & & \\
\hline Fellow ethics & 0.789 & 0.365 & 0.409 & 0.498 & $\mathbf{0 . 8 8 8}$ & & \\
\hline Facility ethics & 0.609 & 0.360 & 0.336 & 0.540 & 0.581 & $\mathbf{0 . 7 8 0}$ & \\
\hline Job satisfaction & 0.664 & -0.365 & -0.432 & -0.514 & -0.561 & -0.594 & $\mathbf{0 . 8 1 5}$ \\
\hline
\end{tabular}

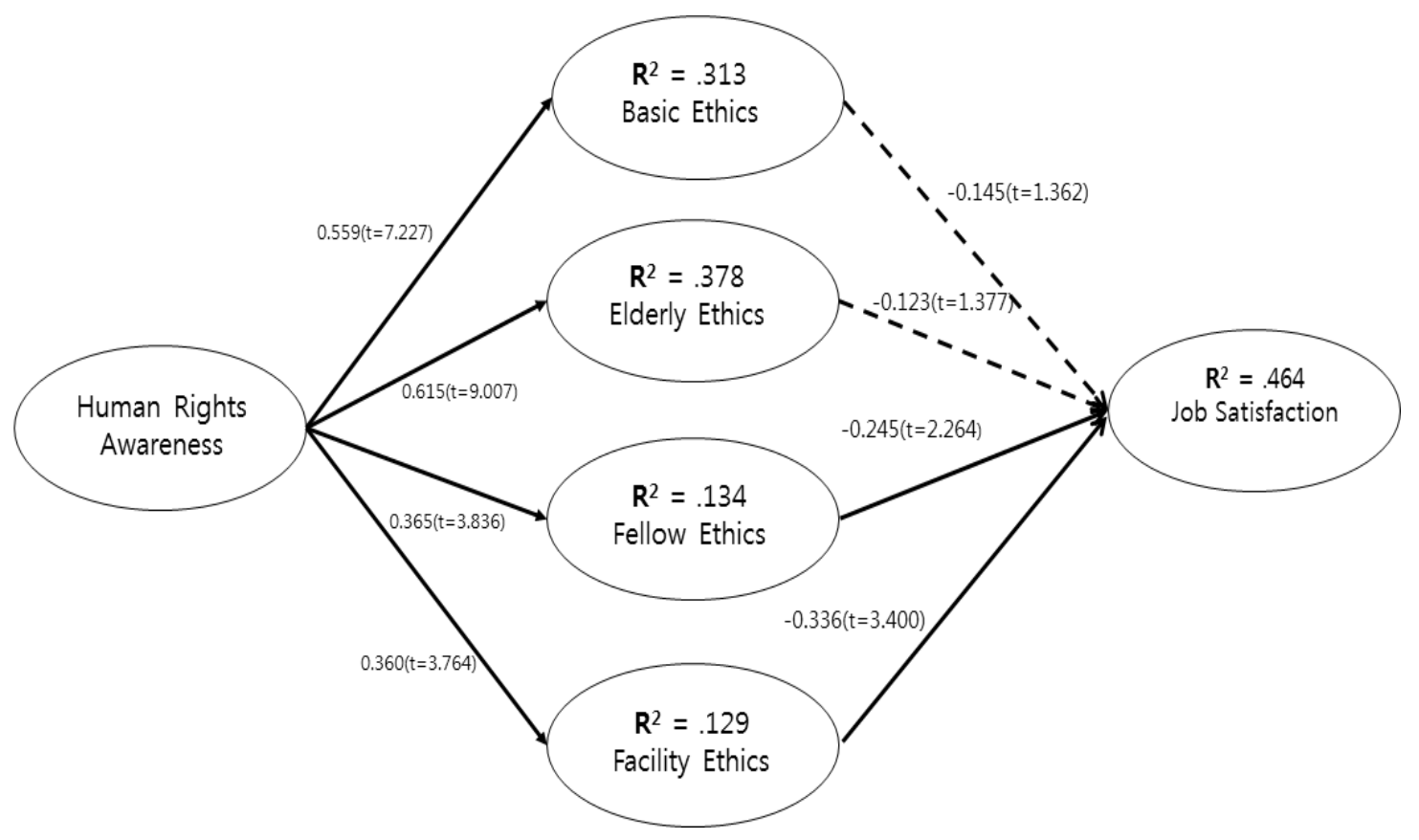

Figure 2. The results of research model 
In Hypothesis H1-1, human rights awareness and basic ethics $(\beta=0.559, \mathrm{t}=7.227, \mathrm{p}<0.05)$ were found to have a significant effect. Among the impacts on work ethics, human rights awareness is based on basic ethics.

In hypothesis H1-2, human rights consciousness and elderly ethics $(\beta=0.615, t=9.007, p$ $<0.05)$ were found to have significant effects. Among the impacts on work ethics, human rights awareness pays attention to elderly ethics.

In Hypothesis H1-3, human rights awareness and fellow ethics $(\beta=0.365, \mathrm{t}=3.836, \mathrm{p}<0.05)$ were found to have significant effects. Among the impacts on work ethics, human rights awareness is based on fellow ethics.

In Hypothesis H1-4, human rights awareness and facility ethics $(\beta=0.360, t=3.764, p<0.05)$ have significant effects. Among the impacts on work ethics, human rights awareness is based on facility ethics.

Hypothesis H2-1 showed no statistically significant relationship between basic ethics and job satisfaction $(\beta=-0.145, \mathrm{t}=1.362, \mathrm{p}>0.05)$. Among the effects on job satisfaction, basic ethics is not significant.

In Hypothesis H2-2, there was no statistically significant relationship between elderly ethics and job satisfaction $(\beta=-0.123, t=1.377, \mathrm{p}>0.05)$. Among the effects on job satisfaction, the elderly ethics are not significant.

In hypothesis H2-3, fellow ethics and job satisfaction $(\beta=-0.245, \mathrm{t}=2.264, \mathrm{p}<0.05)$ were found to have a significant effect. Among the effects on job satisfaction, fellow ethics is significant.

In Hypothesis H2-4, facility ethics and job satisfaction $(\beta=-0.336, t=3.400, p<0.05)$ were found to have a significant effect. Among the effects on job satisfaction, facility ethics is significant.

\section{Conclusion}

Based on the results of this study, the following implications can be suggested. First, a variety of education is needed to improve the human rights awareness of caregivers. Differentiated human rights education should be expanded according to demographic and job characteristics. Second, ethical standards that caregivers can easily recognize and practice in the field of social welfare should be presented. Based on this, regular work ethics education and structural alternatives to enforce some ethical standards should be prepared. Third, in order to secure the human rights awareness and professional ethics of caregivers, it is necessary to take realistic measures to improve job satisfaction, such as improving the welfare level of caregivers and improving the working environment.

The level of human rights awareness and work ethic of caregivers affects job satisfaction. Thus, raising human rights awareness and work ethics can contribute to raising the level of well-being of the elderly by increasing their job satisfaction[7]. However, previous studies have shown low awareness of basic ethics and elderly ethics, such as having private encounters with the elderly or having snacks for the elderly or their guardians [8]. In this study, the basic ethics and the elderly ethics among the work ethics did not have a significant effect on job satisfaction, but this is necessary because of the general characteristics of respondents and the lack of diversity in measuring tools.

\section{References}


[1] I. Son, D. Kim and S. Kim, "A Study on the Impact of Human Rights Awareness on Service Quality and Moderating Effect of Organizational Commitment," Journal of Disability and Welfare, vol.43, pp.213-234, (2019)

[2] http://edu.humanrights.go.kr/academy/, July 29 (2019)

[3] Caregiver Training Standards, "Ministry of Health and Welfare," (2019)

[4] S. Kim, "The study on job satisfaction of care workers between long term and home base care service center," Journal of the Korean Association for Social Service, vol.8, no.2, pp.49-70, (2018)

[5] http://edu.humanrights.go.kr/academy/, August 8, (2019)

[6] J. Shin, "A review of the online game shutdown system, law review," vol.21, no.3, pp.119-147, (2013)

[7] B. Goo, "The influence of the care managers' professional ethics on job satisfaction," M.S. thesis, Graduate School of Welfare, Daegu University, (2011)

[8] J. Yoo, "A study of the effect of professional and the job satisfaction on the ethics of social workers - focused on social workers in Gyeonggi-do “, M.S. thesis, The graduate School of Kyeonggi University, (2010) 